\title{
Dimensioning UX Models for Design and Evaluation
}

\author{
Azham Hussain ${ }^{1}$, Emmanuel O.C. Mkpojiogu ${ }^{2}$, Mohd Zabidin Husin ${ }^{3 *}$ \\ ${ }^{1,2,3}$ School of Computing, Universiti Utara Malaysia, 06010 UUM, Sintok, Malaysia \\ ${ }^{2}$ Department of Computer and Information Technology, Veritas University, Abuja, Nigeria \\ Corresponding author: ${ }^{3} *$ zabidin@uum.edu.my
}

Article History: Received: 10 November 2020; Revised: 12 January 2021; Accepted: 27 January 2021; Published online: 05 April 2021

\begin{abstract}
This paper attempts to find out the available dimensions of user experience models in extant literature. The study observed that there are numerous user experience models with a number of dimensions. This notwithstanding, there appears to be no concord among practitioners and researchers on the dimensioning of UX models. The reason for lack of consensus is due to underlying nature of user experience which signifies that UX should be structured and dimensioned differently dependent on the context and domain of use. Seemingly every experience is particularly unique and is situated in time and context, thus making the dimensioning of UX to vary and differ. A close look at prior literature indicate that several user experience models exist but their dimensions are however not comprehensive enough for a holistic design and evaluation of digital applications experiences. To this end, this study proposed a set of dimensions for interactive systems that will aid a more comprehensive and holistic design and evaluation of the user experience of interactive applications.
\end{abstract}

Keywords: Evaluation, Design, UX dimensions, UX models

\section{Introduction}

A model is an abstract (graphical) representation of real life phenomena. The structure is made up of measurable constructs that are related to each other. These measurable constructs include dimensions and their accompanying criteria. Dimensions on the other hand are measurable constructs associated with a model that serve as a collection of other constructs that are related to each other and that are also related to the model's main construct. In other words, dimensions are the different aspects or facets of a user experience (UX) construct. Essentially, UX dimensions are quality constructs that make up the UX model. They are the aspects or facets of UX qualities as perceived by users as they interact with the software product. Dimensions represent the users organism influenced by design factors (criteria). They are a set of quality attributes that define a user's experience with software product (Hussain et al., 2018; Hussain et al., 2019a; 2019b). There are several identified UX dimensions in literature. The dimensions are as follows: i) interactivity (Othman, Petrie, \& Power, 2011; Schild, LaViola Jr, \& Masuch, 2012); ii) user engagement (Schild, LaViola Jr, \& Masuch, 2012); iii) pragmatic (Bargas-Avila \& Hornbæk, 2011; Lee \& Koubek, 2010); iv) affective (Law et al., 2008); v) hedonic (Cyr, Head, \& Ivanov, 2009; O’Brien, 2010; Korhonen et al., 2009); vi) self-determination (Sheldon et al., 2001; Fronemann \& Peissner, 2014; Sonnleitner et al., 2013); vii) aesthetic (Bargas-Avila \& Hornbæk, 2011; Lee \& Koubek, 2010; Porat \& Tractinsky, 2012); and viii) sociability (Sheldon et al., 2001; Park et al., 2015). It is interesting to note that UX is the totality of users' feelings, perceptions, motivations, preferences, beliefs, attitudes and emotional reactions that result from their encounter or interaction with interactive technological artifact at a given time and context of use (Park et al., 2015; Mkpojiogu et al., 2018; Mkpojiogu et al., 2019; Hassenzahl, 2004)

UX dimensions are needed to fully understand users' experience and to guide design and evaluation. Just as it is for designing for UX, a holistic evaluation of UX is challenging as a result of its dynamic, subjective, and difficult-to-quantify nature. Consequently, Vermeeren et al. (2010) posit that there are no generally accepted standard approaches for the design and evaluation of UX (Olsson, 2012). There is nonetheless a debate among academics on the way UX can and should be designed, measured or evaluated (Law, 2011). While one part of researchers contends for a qualitative approach, others argue in favor of a quantitative approach (Law, 2011; Kraus, 2017). However, some prefer to be in the middle and contend for mixed or hybrid approach (Hart, 2014). The qualitative approach is holistic, design-based, interpretative, narrative, descriptive, requires involvement of stakeholders, dialogical, human-centered, and focus on the uniqueness of experience (Glanznig, 2012). On the other hand, the quantitative approach is model-based, statistical, observational, more objective, precise, and formal, focuses more on evaluation, and allows for benchmarking (Glanznig, 2012). The mixed approach combines the features of the qualitative and the quantitative approaches. As stated earlier, prior research are replete with models with different kinds of dimensions. Researchers and professionals are yet to agree on a standard or uniform dimension for user experience models. Anyway, such standards are difficult to come by because of the very nature of user experience. No two experiences are the same. Also, user experience is contextdependent, and situated in time and within a specified context of interaction. This gives room for further 
unlimited conceptualization of the dimensioning of UX. Table 1 depicts the dimensions of UX as seen in extant literature.

Table 1. UX Dimensions

\begin{tabular}{|l|l|}
\hline Author(s) & UX Dimensions \\
\hline Tractinsky (1997) & Classical \& Expressive aesthetics \\
\hline Jordan (2000) & Functionality, Usability, \& Pleasure \\
\hline Vilnai-Yavetz \& Rafaeli (2005) & Instrumentality, Aesthetics, \& Symbolism \\
\hline Tractinsky \& Zmiri (2006) & Usability, Aesthetics \& Symbolism \\
\hline Hassenzahl (2003, 2004) & Pragmatic \& Hedonic \\
\hline Wright et al. (2003, 2008) & Sensual, Emotional, Spatio-temporal, \& Compositional \\
\hline Thuring \& Mahlke (2007) & Instrumental, Non-instrumental \& Emotional \\
\hline Mahlke (2008) Padovani (2007); & Instrumental \& Non-instrumental \\
\hline $\begin{array}{l}\text { Buccini \& Emental, Cognitive \& Epistemic, Emotional, Sensory, Social, } \\
\text { Olsson (2012) }\end{array}$ & Motivational \& Behavioral, \\
\hline Park et al. (2015) & Utilitarian, Affective \& Sociability \\
\hline
\end{tabular}

Table 1shows prior studies that classified UX into major categories that can be termed dimensions of UX. Tractinsky (1997) was one of the earliest studies to break down UX into measurable dimensions. Jordan (2000) classified UX into functionality, usability and pleasure. Vilnai-Yavetz and Rafaeli (2005) broke down UX into instrumentality, aesthetics and symbolism. Tractinsky and Zmiri (2006) on their part drew on the work of Rafael and Vilnai-Yavetz (2004) to propose three distinct product quality attributes: usability, aesthetics and symbolism. Forlizzi extended this model to further account for the emotional and social aspects of product use. Hassenzahl $(2003,2004)$ modeled UX into two dimensions, namely: pragmatic and hedonic, he distinguished between two quality perceptions: pragmatic and hedonic. Pragmatic quality refers to the product's ability to support the ergonomic achievement of behavioral goals (that is, usefulness and ease-of-use). Hedonic quality on the other hand refers to the users' self and wellbeing. It relates to stimulation, that is, the product ability to stimulate and enable personal growth, and identification, that is, the product's ability to address the need of expressing one's self through objects one owns. Hassenzahl (2004) suggested two distinct overall evaluative judgments of the quality of interactive products: beauty and goodness. He found that goodness is affected primarily by pragmatic aspects (that is, usefulness, functionality and usability). However, he found beauty to be a rather social aspect, largely affected by identification (that, is, the product's ability to address the needs of self-expression). Tractinsky's (1997) expressive aesthetics compares to Hassenzahl's (2004) stimulation.

Mahlke (2008) viewed UX as consisting of instrumental and non-instrumental dimensions. Olsson (2012) in a more recent work described and classified UX based on the typology by Buccini and Padovani (2007) with some slight condensation and refinement. The identified classifications of UX were categorized further into six categories that signify UX, namely: instrumental experiences, cognitive and epistemic experiences, emotional experiences, sensory experiences, motivational experiences, and social experiences. Recently, Park (2015) unloaded UX as consisting of utilitarian, affective and sociability dimensions. The above studies did not reflect the holistic nature of UX as none of the studies included the totality of the dimensions of UX. A literature review unveiled that there are more dimensions that make up UX (such as, interactivity, affectivity, engage ability, playfulness, etc.). These dimensions were not studies or encapsulated collectively in any single study. Furthermore, literature review also revealed the different attributes that are associated with the discovered dimensions. This present study delved into literature and extracted a more holistic and comprehensive dimensions of user experience that are useful for the design and evaluation of the user experience of interactive systems/products.

\section{Methodology}

This study used literature content analysis strategy to x-ray the content of available literature to find out the various dimensioning of user experience. The protocol observed in the doing this include: i) downloading appropriate literature sources on the dimensioning of UX; ii) synthesizing the sources for information of UX model dimensions; iii) extracting information relating to user experience dimensions relating to the models of UX; iv) uncovering gaps in the discovered dimensions; v) proposing a fuller, more holistic and comprehensive dimensions for the UX of interactive applications. Figure 1 illustrates the research methods employed in this study. 


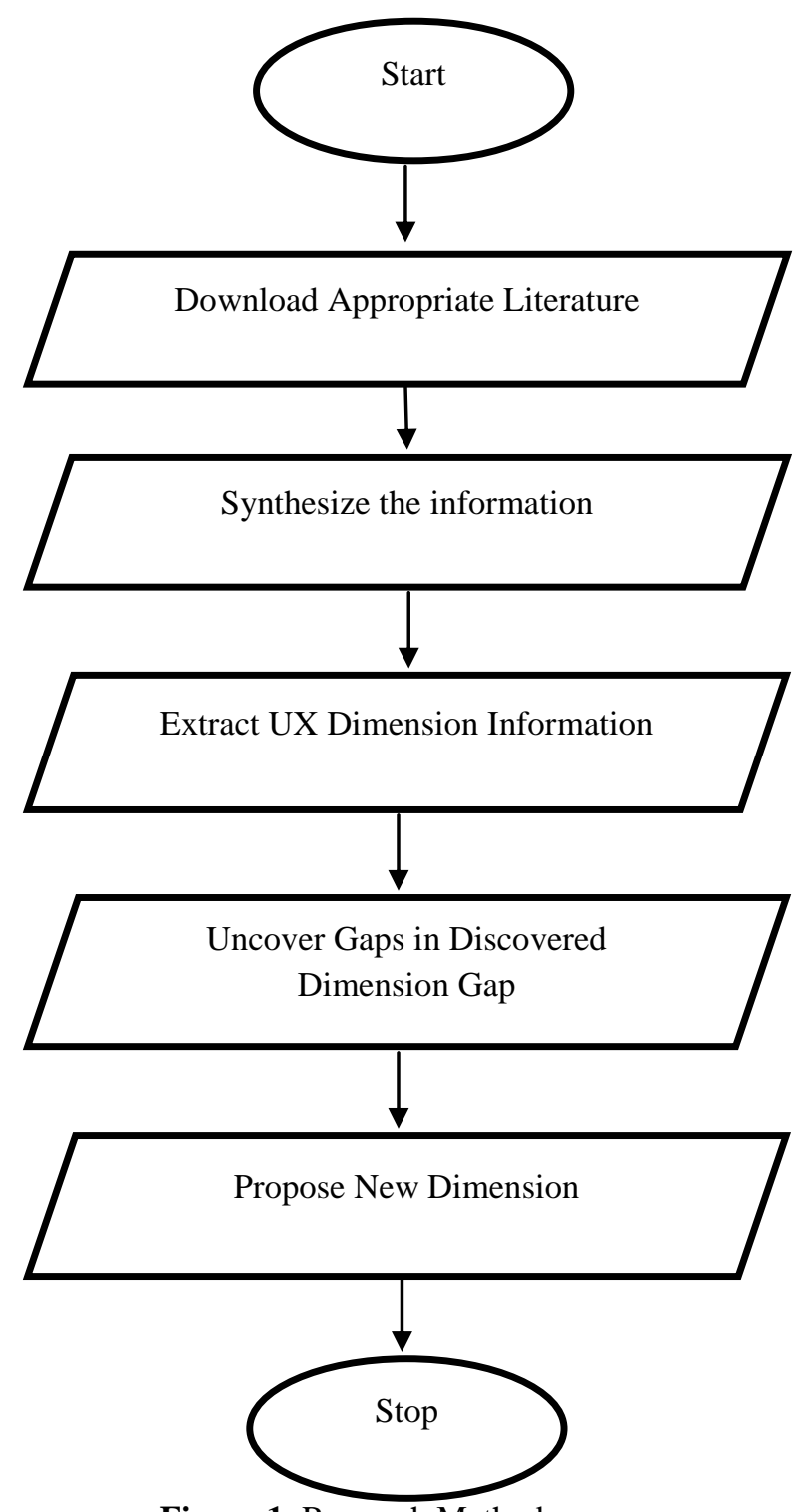

Figure 1. Research Method

\section{Results}

Table 2 indicates the uncovered dimensions that this paper is proposing. These dimensions are more holistic and comprehensive for the design and evaluation of the user experience of interactive digital artifacts.

Table 2. UX Dimensions

\begin{tabular}{|l|l|}
\hline Dimensions & Sources \\
\hline Pragmatics & Lew \& Olsina (2017); Hassenzahl (2018); Santoso et al. (2017) \\
\hline Hedonics & Hancock et al. (2015); Hassenzahl (2018) \\
\hline Affectivity & $\begin{array}{l}\text { Minge, Wagner \& Kuhr (2016); Lew \&Olsina (2017); Santoso et al. (2017); Takatalo et al. } \\
(2008)\end{array}$ \\
\hline Aesthetics & Tractinsky (1989) \\
\hline $\begin{array}{l}\text { Self- } \\
\text { Determination }\end{array}$ & Sheldon et al. (2001) \\
\hline Trust & Lew \& Olsina (2017) \\
\hline Engageability & Takatalo et al. (2008); Olsson (2012); Tojib \&Tsarenko (2012) \\
\hline Interactivity & Takatalo et al. (2008); Cyr, Head \& Ivanov (2009) \\
\hline
\end{tabular}




\begin{tabular}{|l|l|}
\hline Sociability & Park et al. (2015); Santoso et al. (2017) \\
\hline Ubiquity & Okazaki \& Mendez(2013); Hong and Tam (2006) \\
\hline
\end{tabular}

Pragmatic dimension consists of UX constructs that are ergonomic, product related, task-oriented and that meet the users' do goals. They reflect on the usability, simplicity, navigability, learnability, understandability, usefulness, and functionality etc. Aesthetic dimension comprise of UX qualities that reflect users' perceptions and qualities of beauty, styling, color, form, captivation, harmony, balance, creativity, neatness, originality, calm, hue, brightness, shape, texture, conventional, innovation, perceived layout, visual appealingness and attractiveness, cleanness, and fascinating, clear, symmetrical, and well organized design, etc. It consists of both the classical and expressive aspects of aesthetics. Hedonic dimension is built with UX qualities that are humanoriented and that meet the be-goals of users (psychological needs of users). The dimension includes the qualities of pleasure, delightfulness, symbolism, personalization, and individual fulfillment. Affectivity dimension connects UX qualities that relate with users emotional reaction or response to interactive systems. As observed from literature, the attributes that associate with this dimension are: valence, arousal, dominance and evocation. Interactivity dimension holds the UX qualities that measure interactivity of users. The quality attributes encapsulated in this dimension are: user control, connectedness, responsiveness, and personalization. Selfdetermination dimension groups the UX qualities (design criteria) that measure users' self-determination. The dimension defines how users perceive a given interactive product's ability to enable them interact with it without external assistance (or influence) and how intrinsically motivated they are to interact with the products. The dimension defines users' feeling that they are capable of interacting with the product independently. These needs are critical to the UX of users. The attributes contributing to this dimension are: autonomy, competence, stimulation, self-efficacy, and relatedness.

Other dimensions are: Engage ability dimension: This dimension measures user engagement with a technological artifact. The dimension consists of the following qualities: flow, presence, and playfulness. Next is Sociability dimension: This dimension is an umbrella quality that comprises of constructs that measure user's social relationships, their sense of belongingness and co-engagement during interaction with technology. The attributes that build this dimension are: relationship, socio-cultural, equality, identity and co-presence. Trust Dimension: This dimension is a collection of trust related qualities. This dimension comprises of the following qualities: privacy, security, credibility, dependability and transparency. Finally, is the Ubiquity Dimension: This dimension encompasses the qualities that measure the anywhere, anytime availability of interactive systems. The following related qualities are associated with ubiquity: immediacy, continuity, and locality.

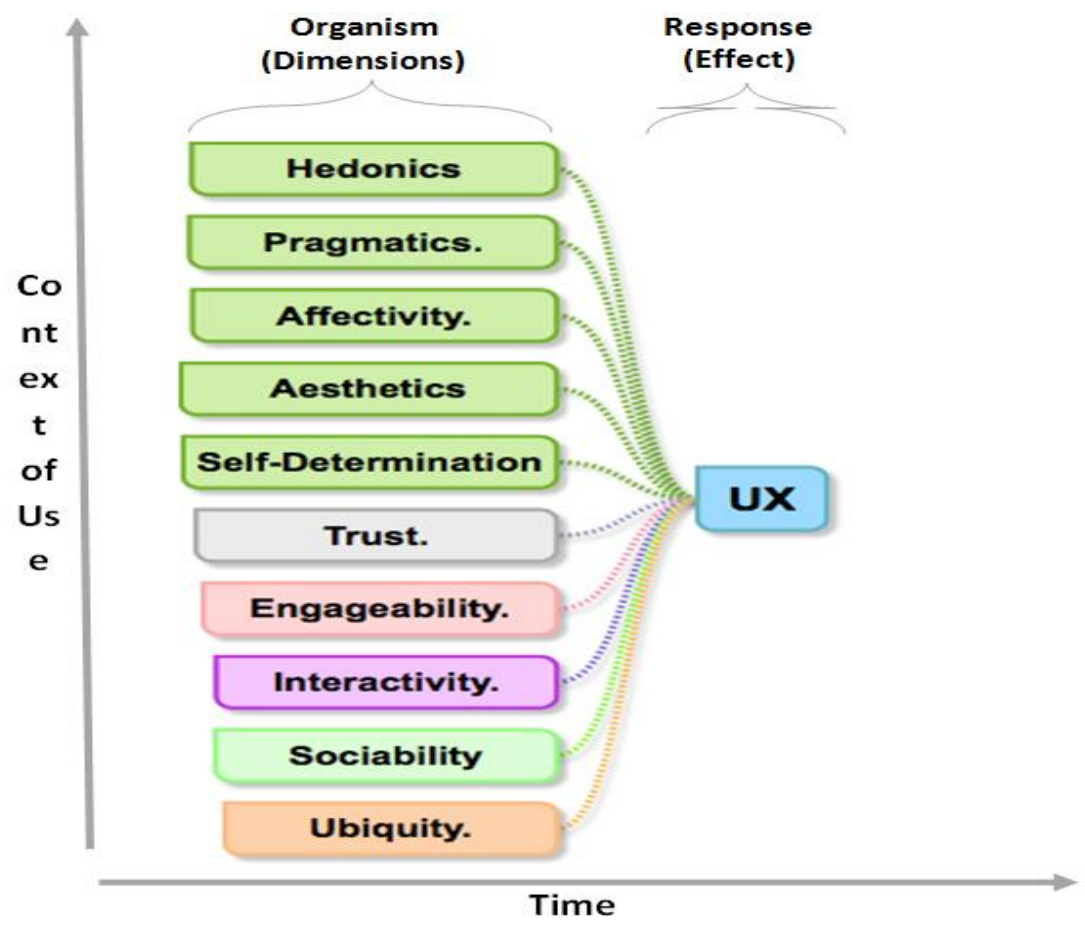

Figure 2. A Proposed UX Model for the Design and Evaluation of Interactive Products 


\section{Conclusion}

In this study, an attempt was made to know and understand the available dimensions of user experience models in literature. It was observed that there are several UX models with several dimensions. However, there seem to be no consensus on the dimensioning of user experience models. The reason for lack of agreement is not far-fetched since the very nature of user experience portends that UX should be dimensioned differently depending on the context of interaction and domain of use. Apparently every experience is unique and is situated in time and context making the dimensioning to vary. A cursory look at extant literature reveal that a number of user experience models exist but their dimensioning is not holistic enough for a comprehensive design and evaluation of digital applications. Following this gap, this study proposed a set of dimensions for interactive systems that will aid a more holistic and comprehensive design and evaluation of interactive applications.

\section{References}

1. Bargas-Avila, J.A., \& Hornbæk, K. (2011). Old wine in new bottles or novel challenges: a critical analysis of empirical studies of user experience. In Proceedings of the SIGCHI Conference on Human Factors in Computing Systems (CHI), (pp.2689-2698). ACM.

2. Buccini, M. \& Padovani, S. (2007). Typology of experiences. Proceedings of DPPI'07. ACM Press, pp. 495-504.

3. Cyr, D., Head, M., \& Ivanov, A. (2009). Perceived interactivity leading to e-loyalty: Development of a model for cognitive-affective user responses. International Journal of Human-Computer Studies, 67(10), 850-869.

4. Fronemann, N., \& Peissner, M. (2014). User experience concept exploration: user needs as a source for innovation. In Proceedings of the 8th Nordic Conference on Human-Computer Interaction (nordiCHI): Fun, Fast, Foundational, (pp. 727-736), ACM.

5. Glanznig, M. (2012). User experience research: modeling and describing subjective. Interdisciplinary Description of Complex Systems, 10 (3), 235-247.

6. Hart, J. (2014). Investigating user experience and user engagement for design. Doctoral Dissertation, Manchester University.

7. Hassenzahl, M. (2003). The thing and I: understanding the relationship between user and product. In Blythe, M., Monk, A.F., Overbeeke, K., Wright, P. (eds.), Funology: from usability to enjoyment, (pp. 31-42), Kluwer.

8. Hassenzahl, M. (2004).The interplay of beauty, goodness, and usability in interactive products. Human-Comp. Interaction, 19(4), 319-349.

9. Hussain, A., Mkpojiogu, E.O.C. \& Hassan, F. (2018). Dimensions and sub-dimensions for the evaluation of m-learning apps for children: A review. International Journal of Engineering \& Technology (IJET), 7 (3.20), 291-295.

10. Hussain, A., Mkpojiogu, E.O.C. \& Kutar, M. (2019a). The impact of software features' perceived importance on the perceived performance of software products' quality elements. Journal of Computational and Theoretical Nanoscience. 16 (5-6), 2135-2140.

11. Hussain, A., Shamala, P., \& Mkpojiogu, E.O.C. (2019b). The effect of software features' perceived importance on the observed performance of software product qualities. Journal of Advanced Research in Dynamical and Control Systems (JARDCS), 11(08-SI), 1076-1082.

12. Jordan, P. W. (2000). Designing pleasurable products: An introduction to the new human factors. Taylor \& Francis.

13. Korhonen, H., Montola, M., \& Arrasvuori, J. (2009).Understanding playful user experience through digital games. In International Conference on Designing Pleasurable Products and Interfaces(pp. 274-285).

14. Kraus, L. (2017). User experience with mobile security and privacy mechanisms. Doctoral Dissertation, Technischen Universitat Berlin.

15. Law, E.L. (2011). The measurability and predictability of user experience. In Proceedings of the 3rd ACM SIGCHI Symposium on Engineering Interactive Computing Systems (EICS).ACM, (pp. 1-10).

16. Law, E., Roto, V., Vermeeren, A., Kort, S., \& Hassenzahl, M. (2008).Towards a shared definition of user experience. Association of Computing Mechinery.

17. Lee, S., \& Koubek, R. J. (2010). The effects of usability and web design attributes on user preference for e-commerce web sites. Computers in Industry, 61(4), 329-341.

18. Mahlke, S. (2008). User experience of interaction with technical systems: theories, methods, empirical results, and their application to the development of interactive systems. Doctoral dissertation, Belin: Berlin University of Technology. 
19. Mkpojiogu, E.O.C., Hashim, N.L., Hussain, A., \& Tan, K.L. (2019).The impact of user demographics on the perceived satisfaction and comfort of use of m-banking apps. International Journal of Innovative Technology and Exploring Engineering, 8(8S), 460-466.

20. Mkpojiogu, E.O.C., Hussain, A., \& Hassan, F. (2018). A systematic review of usability quality attributes for the evaluation of mobile learning applications for children. ICAST 2018, AIP Conf. Proc. 2016, https://doi.org/10.1063/1.5055494

21. O'Brien, H. L. (2010). The influence of hedonic and utilitarian motivations on user engagement: The case of online shopping experiences. Interacting with Computers, 22(5), 344-352.

22. Olsson, T. (2012).User expectations and experiences of mobile augmented reality services. Tampere University of Technology, Tampere.

23. Othman, M. K., Petrie, H., \& Power, C. (2011). Engaging visitors in museums with technology: scales for the measurement of visitor and multimedia guide experience. In Human-Computer Interaction-INTERACT 2011 (pp. 92-99).Springer Berlin Heidelberg.

24. Park, J., Han, S.H., Lee, M., \& Jang, H. (2015). A literature survey on UX design properties and principles of smart device design for the disabled.

25. Porat, T., \& Tractinsky, N. (2012).Its a pleasure buying here: the effects of web--store design on consumers emotions and attitudes. Human-Computer Interaction, 27(3), 235-276.

26. Schild, J., LaViola Jr, J. J., \& Masuch, M. (2012).Understanding user experience in stereoscopic 3D games. In Proceedings of the SIGCHI Conference on Human Factors in Computing Systems(pp. 89-98).ACM.

27. Sheldon, K. M., Elliot, A. J., Kim, Y., \& Kasser, T. (2001). What is satisfying about satisfying events? Testing 10 candidate psychological needs. Journal of personality and social psychology, $80(2), 325$.

28. Sonnleitner, A., Pawlowski, M., Kässer, T., \& Peissner, M. (2013). Experimentally manipulating positive user experience based on the fulfilment of user needs. In: Human-Computer InteractionINTERACT 2013. (pp.555-562), Springer.

29. Thüring, M. \& Mahlke, S. (2007). Usability, aesthetics, and emotions in human-technologyinteraction.International Journal of Psychology, 42, 253-264.

30. Tractinsky, N. (1997). Aesthetics and apparent usability: empirically assessing cultural and methodological issues. In Proceedings of the ACM SIGCHI Conference on Human factors in computing systems (pp. 115-122).ACM.

31. Tractinsky, N., \& Zmiri, D. (2006).Exploring attributes of skins as potential antecedents of emotion in HCI.In Aesthetic computing (pp. 405-422).

32. Vermeeren, A. P., Law, E. L.-C., Roto, V., Obrist, M., Hoonhout, J., \& Väänänen-Vainio-Mattila, K. (2010). User experience evaluation methods: current state and development needs. In Proceedings of the 6th Nordic Conference on Human-Computer Interaction

33. Vilnai-Yavetz, I., \& Rafaeli, A. (2005). Instrumentality, aesthetics, and symbolism of office design. Environment and Behavior, 37(4), 533-551.

34. Wright, P., McCarthy, J., \& Meekison, L. (2003).Making sense of experience.” In: Funology. (pp.43-53), Springer.

35. Wright, P., Wallace, J., McCarthy, J. (2008). Aesthetics and experience-centered design. Transactions on Comp.-Human Interaction, 15(4), 21. 